\title{
Voltage Profile Improvement using DG in Reconfigured Distribution System
}

\author{
S Vidyasagar ${ }^{1 *}$, K Vijayakumar ${ }^{2}$, R Ramanujam $^{3}$, D.Sattianadan ${ }^{4}$ and Noraj \\ Kumar $^{5}$ \\ 1,2,3,4,5 Department of EEE, SRM University, Tamilnadu, India \\ mailsvs@gmail.com
}

\begin{abstract}
In today's trend, the importance of Distributed Generation $(D G)$ implementation in the distribution system $(D S)$ becomes more significant with respect to proper location, sizing and reduction of losses. In this paper the location and size of $D G$ were discussed based on Voltage Limitation Index (VLI). This index is used to ensure that all the buses in the network have acceptable voltage profile according to the distribution permissible limits. After determining the $D G$ size and location a comprehensive analysis on cost of DG, energy loss occurred and savings obtained in the network were listed. The significance of VLI was tested on IEEE 33 and 69 bus DS under initial configuration state as well as in feeder reconfigured state also.
\end{abstract}

Keywords: Distributed Generation, Feeder Reconfiguration, Voltage Limitation Index and Distribution Automation

\section{Introduction}

DG now-a-days has become a promising alternative potential to compensate or reduction of losses that occurs in a distribution system. Renewable energy based DG has been introduced in the recent years in order to shrink the usage of fossil fuels in the electric power generation mitigating power losses and avoid pollution due to emission[12]. By introducing DG in radial distribution network, its influence over voltage stability, loss reduction, load balancing and power quality issues were discussed in [3-4]. In [5] the objectives such as power loss reduction, voltage profile enhancement and energy loss reduction with simultaneous placement of DG and capacitor in distribution network at various load levels employed by using memetic algorithm. Comparison of Novel loss sensitivity index and Voltage Sensitivity Index (VSI) is shown in [6]. The new long term scheduling for optimal allocation and sizing of DG [7] by employing Power Stability Index (PSI) and PSO [8-9]. Different methodologies for DG allocation are presented in [10]. A combined genetic algorithm (GA) and Particle Swarm Optimization (PSO) is proposed in [11]. Multi-objective performance index (MOPI) based optimal location and sizing of DG for improving voltage stability was discussed in [12]. Reactive power control of DG in medium voltage (MV) distribution network [13] and various types of DG are proposed in [14-15] for minimizing power loss and optimal power factor for supplying DG is discussed. Technical and economical factors are considered for obtaining optimal sizing of DG [16]. Optimum planning of DG under various aspects is shown in [17]. FR in balanced and unbalanced networks by using simultaneous reconfiguration and DG allocation is in [18] with D.T Le and M. A. Kashem explaining how to maximize voltage support by using DG and various methodologies related to DG placement are also proposed[19]. Kazem Haghdar and Heidar Ali Shayanfar proposed a new method of generalized pattern search and genetic algorithm for optimal placement of DG and capacitor for loss reduction [20]. A simple vector based load flow technique [21] is proposed for optimizing cost and placement of DG. An algorithm based on multi- 
objective approach in which placement of DG for loss minimization and enhancing voltage stability both are considered [22]. In [23] a combined strategy is proposed by using local and size optimization in order to achieve local and global search ability of artificial bee colony and ant colony optimization. In [24] a multi-objective index is proposed for determining the optimal sizing and power factor of DG for improving loadability. A Shuffled Frog Leaping Algorithm [25], mixed integer linear programming method [26-27], Multi-objective PSO with preference strategy [28] and Bacterial Foraging [29] are proposed to solve the problem of multi-objective DG sizing and placement. From the literature survey it was clear that only the location and sizing were given importance and not about the voltage limits, so a work was proposed in order to view the significance of voltage profile under distribution limits. The distribution limits is considered as $\pm 6 \%$.

This paper is organized as introduction in section-2, Problem formulation as section-3 and results were discussed in section- 4 .

\section{Problem Formulation}

The Voltage Limitation Index is given as follows

$$
V L I=\left[V_{i}-V_{\text {limit }}\right]^{2}
$$

Where $V_{\text {limit }}=0.94$ p.u and $V_{i}$ is the $i^{\text {th }}$ bus voltage.

\section{Cost of Energy Loss and Cost of DG:}

Cost of energy loss and cost of DG is calculated based on mathematical expression given as

Cost of energy loss $(\mathrm{CL})=($ Total real power loss $) \times\left(E_{c} \times T\right) \$$

Where $E_{c}=$ energy rate in $\$ / \mathrm{kWh}(0.06 \$ / \mathrm{kWh})$.

$T=$ time duration in hrs (8760 hrs)

Cost of DG for real and reactive power [35-36]

$$
\begin{aligned}
C(P d g)=a \times P d g^{2}+b \times P d g+c \$ / \mathrm{hr} \\
C(Q d g)=\left[\operatorname{cost}(\mathrm{Sgmax})-\operatorname{cost}\left(\sqrt{S g \mathrm{max}^{2}-Q g^{2}}\right)\right] \times k \$ / h r \\
S g \mathrm{max}=\frac{P g \mathrm{max}}{\cos \phi} \\
P \max =1.1 \times P g \\
k=0.05-1
\end{aligned}
$$

In this paper, the $\mathrm{k}$ factor is taken as 0.1 . 


\section{Results and Discussion}

\subsection{3-Bus Test System}
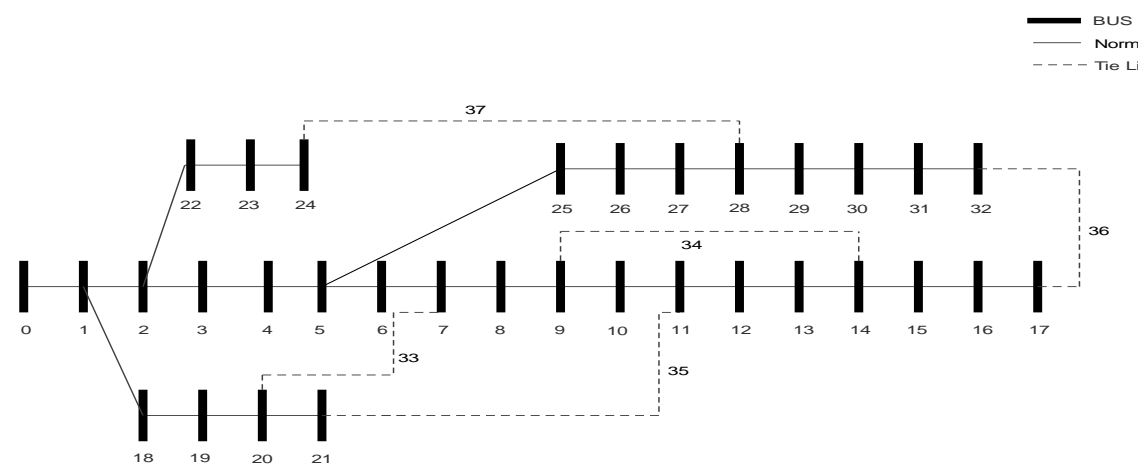

Figure 1. Schematic Diagram of IEEE 33-Bus Test System

For 33-bus Radial distribution network, Active power load=3.71MW, Substation voltage $=12.66 \mathrm{KV}$, Voltage limit $=1.00 \mathrm{pu}$ and Reactive power load $=2.31 \mathrm{Mvar}$. From the below mentioned tabulation listed while performing the load flow, it was observed that real power loss $\left(P_{L}\right)=223.8788$, Reactive power loss $\left(Q_{L}\right)=149.0574$.

Table 1. Results Obtained For 33-Bus Test System Using VLI

\begin{tabular}{|c|c|c|c|c|c|c|}
\hline Parameters & $\begin{array}{c}\text { Base } \\
\text { case }\end{array}$ & $\begin{array}{c}\text { Base } \\
\text { case } \\
\text { with DG }\end{array}$ & $\begin{array}{c}\text { Base case } \\
\text { with DG } \\
\text { along VLI }\end{array}$ & FR & $\begin{array}{c}\text { FR } \\
\text { with DG }\end{array}$ & $\begin{array}{c}\text { FR } \\
\text { with DG } \\
\text { along VLI }\end{array}$ \\
\hline DG location & 18 & 18 & 18 & ---- & 30 & 30 \\
\hline $\begin{array}{c}\text { DG size } \\
\text { (MW) }\end{array}$ & --- & 0.93 & 17.1 & ---- & 1.5 & 0.3264 \\
\hline $\begin{array}{c}\text { Total real } \\
\text { (K.W) } P_{L}\end{array}$ & 223.878 & $\begin{array}{l}213.654 \\
8\end{array}$ & 362.8340 & 141.162 & 129.9026 & 137.8601 \\
\hline $\begin{array}{c}\text { Total(K.Var) } \\
Q_{L}\end{array}$ & 149.057 & $\begin{array}{l}141.857 \\
0\end{array}$ & 243.6654 & 99.2525 & 91.3819 & 96.8407 \\
\hline $\begin{array}{c}\text { Min. bus } \\
\text { voltage @ bus }\end{array}$ & 0.9134 & 0.9185 & 0.9401 & 0.9387 & 0.9448 & 0.94 \\
\hline VLI & 6.3130 & 4.1244 & 0 & 0.0024 & 0 & 0 \\
\hline $\begin{array}{c}\text { Cost of } \\
(\$ / h r)\end{array}$ & ----- & 18.85 & 342.25 & ---- & 30.25 & 6.778 \\
\hline $\begin{array}{c}\text { Cost of energy } \\
\text { loss }(\$ / h r)\end{array}$ & 26.865 & 25.638 & 43.5400 & 16.9634 & 15.5883 & 16.5432 \\
\hline $\begin{array}{c}\text { Savings in cost } \\
\text { of energy loss }\end{array}$ & ------ & 1.227 & $\begin{array}{c}\text { Not } \\
\text { applicable }\end{array}$ & ---- & 11.2767 & 10.3218 \\
\hline
\end{tabular}


The results of Base case without DG is represented in Figure 2. Under the initial configuration state with $18^{\text {th }}$ bus as minimum voltage profile location $V_{18}=0.9134$ (Figure 3). The VLI obtained as 6.3130 for which the DG was suggested. The cost of energy loss is calculated as 26.865. Base Case with DG focusing on DG Size alone is shown in figure 4. For the same case as it was identified $18^{\text {th }}$ location with minimum voltage profile as 0.9185 which can be taken as location of allocating DG with size 0.93 we are getting $P_{L}=213.6548, Q_{L}=141.8570$ at $18^{\text {th }}$ bus. Real Power Loss versus DG Size for base case is shown in figure 5. The VLI obtained is 4.1244 (Figure 3). But even when losses are reduced the savings obtained from the energy loss cost is only around $1.227 \$ / \mathrm{hr}$, with cost for the DG as $18.85 \$ / \mathrm{hr}$. when it is observed with DG along with VLI the savings occurred for the initial configuration was very less since the DG size was too high even though VLI has reached zero. Figure 6 represents the Feeder Reconfiguration without DG. So it recommended for doing Feeder Reconfiguration (FR) for the same network, it was observed that there is more loss reduction compared to initial configuration $P_{L}=141.13623, Q_{L}=99.2525, V_{\text {min }}=0.9381, \mathrm{VLI}=0.0024$ where it is $99.961 \%$ compared to the initial configuration and the cost of energy loss is obtained as 16.9634 which is $36.857 \%$ compared to the base case still since voltage have not reached the limitation of 0.94 under FR state. Figure 8 shows FR with DG focusing on VLI. DG was suggested to the network. Voltage Profile versus Bus number under Base case and FR is shown in Figure 9 and Figure 10. Real Power Loss versus DG Size under Feeder Reconfiguration is shown in figure 11. The location allocated for DG is $30^{\text {th }}$ bus with the DG size of $1.5 \mathrm{MW}$ at cost of $30.25 \$ / \mathrm{hr}$ even though with the minimum voltage is at $32^{\text {nd }}$ bus $P_{L}=129.9026$, $Q_{L}=91.3819$ and cost of energy is calculated as $15.5883 \$ / \mathrm{hr}$ with the savings of $11.2767 \$ / \mathrm{hr}$. since the work is focusing on significance of VLI to maintain 0.94 p.u the DG size required is $0.3264 \mathrm{MW}$ instead of $1.5 \mathrm{MW}$ as in the earlier case the results obtained $P_{L}=137.8601, Q_{L}=96.8407$ with cost of DG as $6.778 \$ / \mathrm{hr}$ even though the results for savings in FR with DG along VLI is comparatively lesser than FR with DG case but the cost of DG increases profit of $77.59 \%$. Size and cost of DG is shown in Figure 12 and 13. Cost and savings of energy losses are shown in Figure 14 and 15.

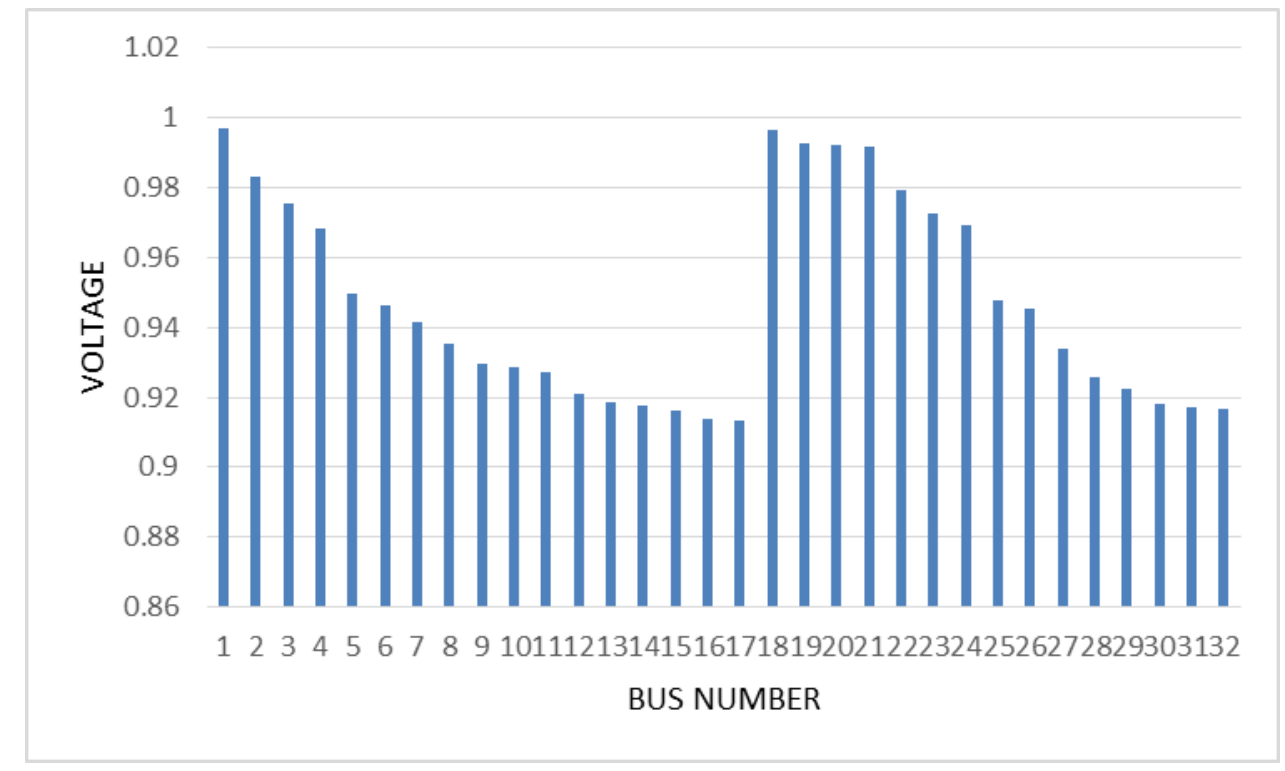

Figure 2. 33 Bus-Base Case without DG 


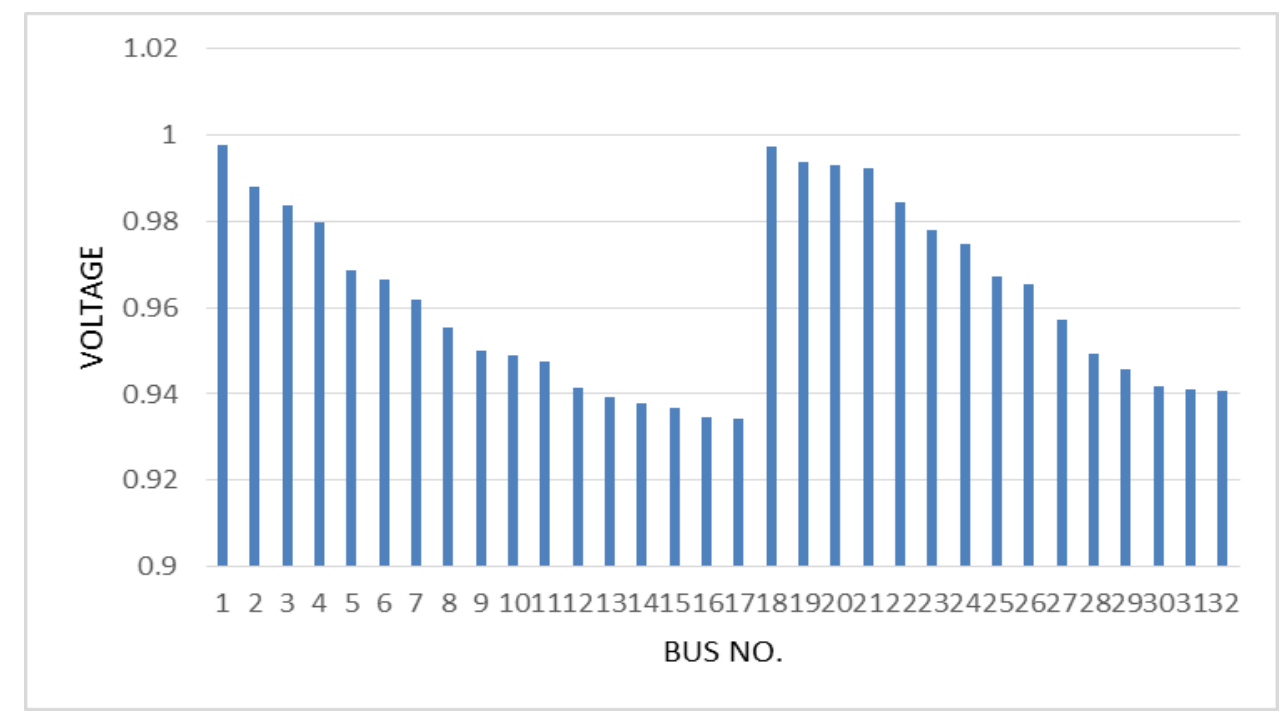

Figure 3. 33 Bus-Base Case with DG Considering VLI

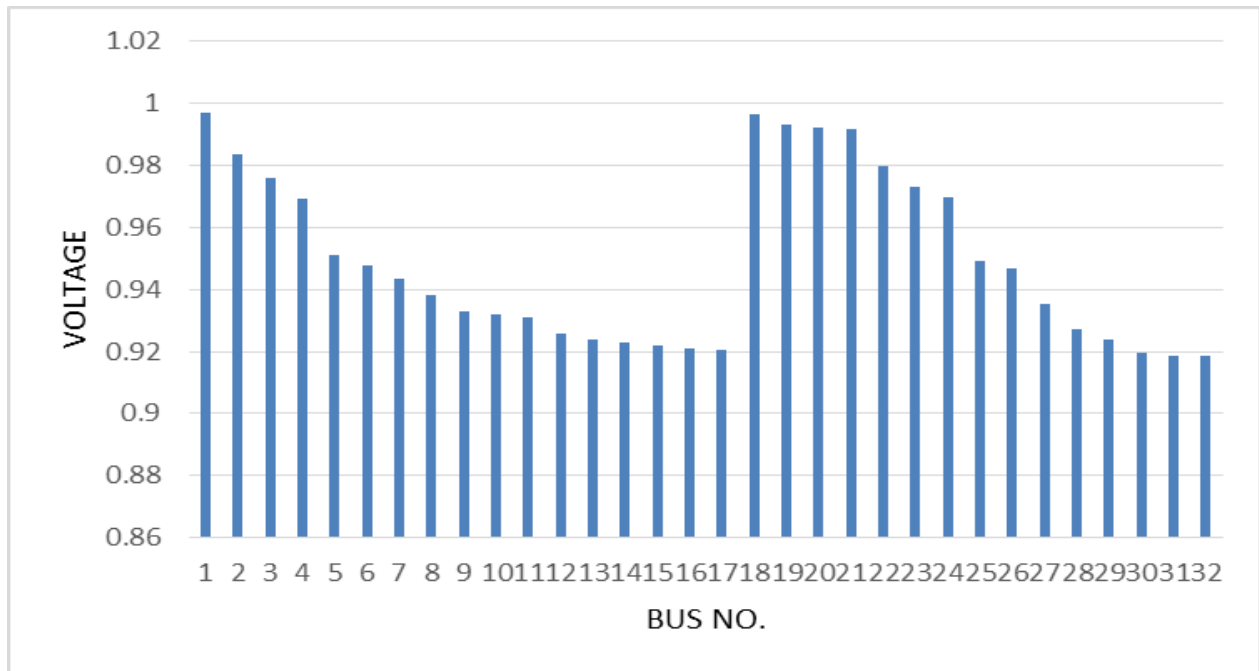

Figure 4. 33 Bus-Base Case with DG Focusing On DG Size

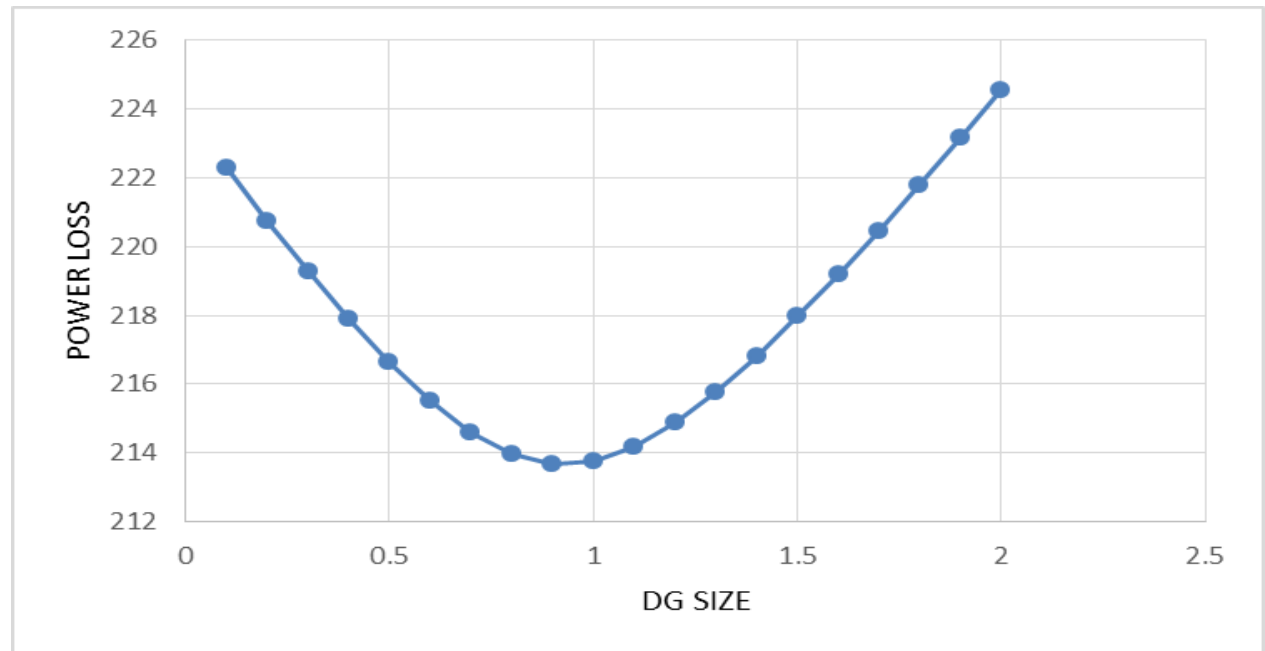

Figure 5. 33 Bus-Real Power Loss V/S DG Size (Base Case) 


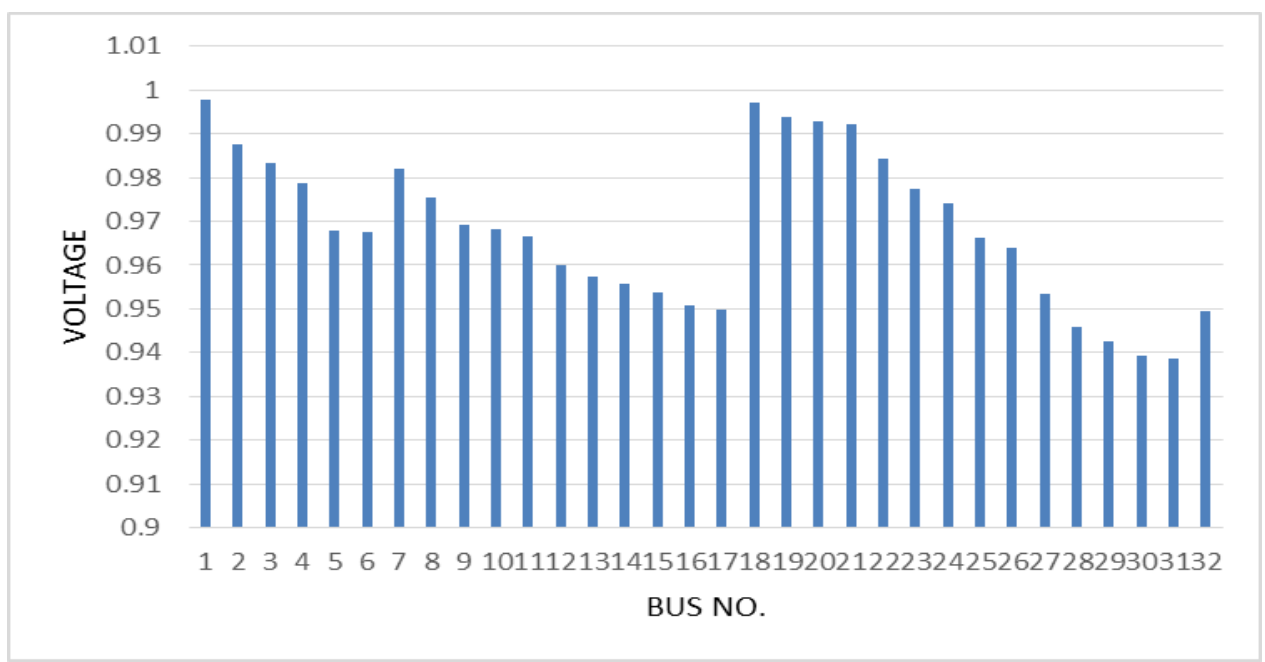

Figure 6. 33 Bus-Feeder Reconfiguration Without DG

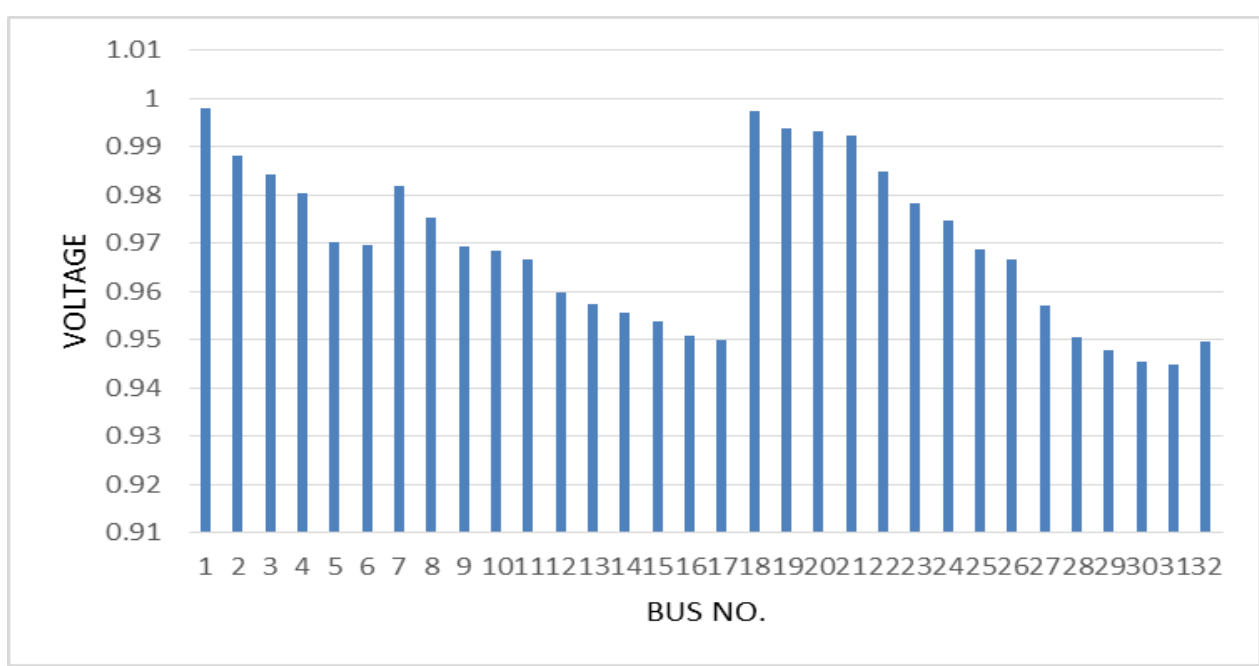

Figure 7. 33 bus-FR with DG (optimal size)

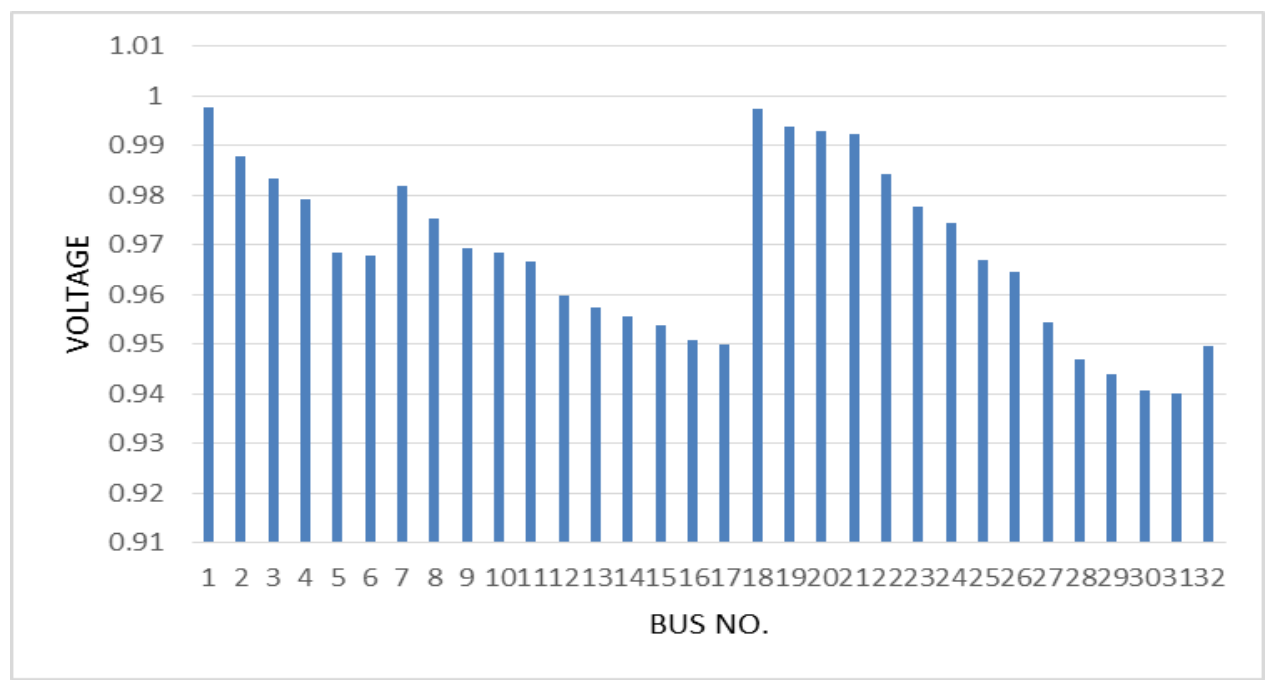

Figure 8. 33 Bus-FR with DG (Focusing On VLI) 


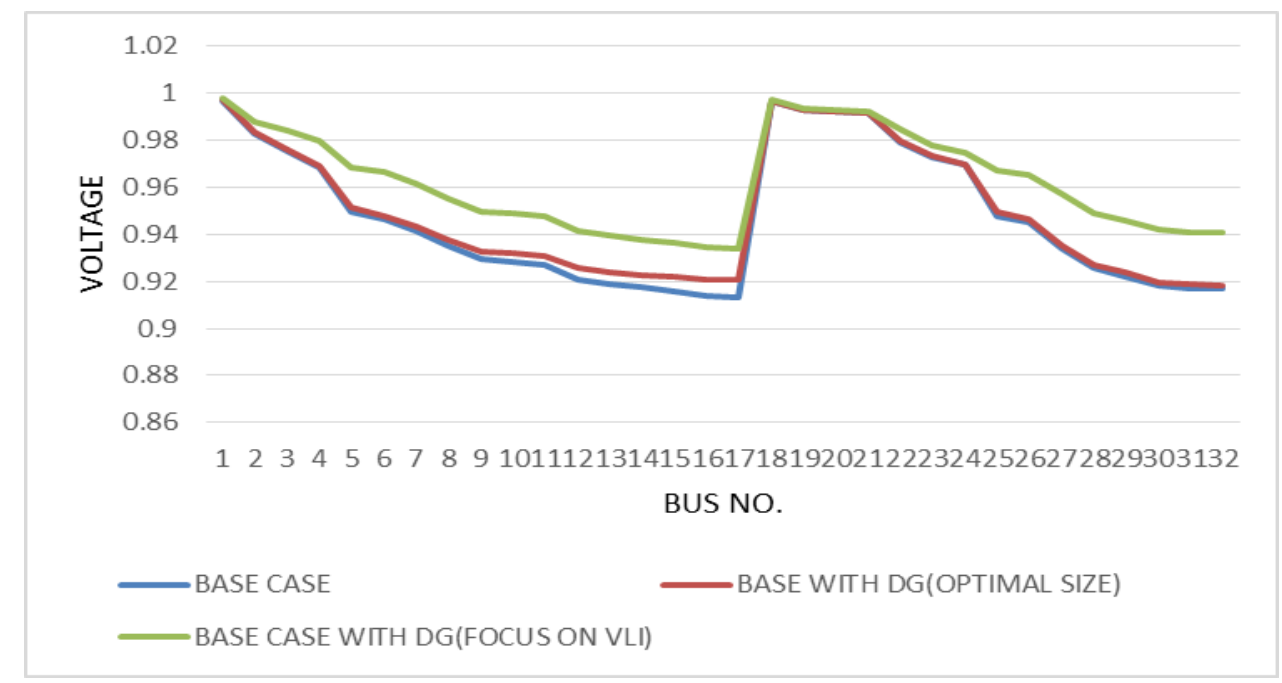

Figure 9. 33 Bus- Voltage Profile V/S Bus Number under Base Case

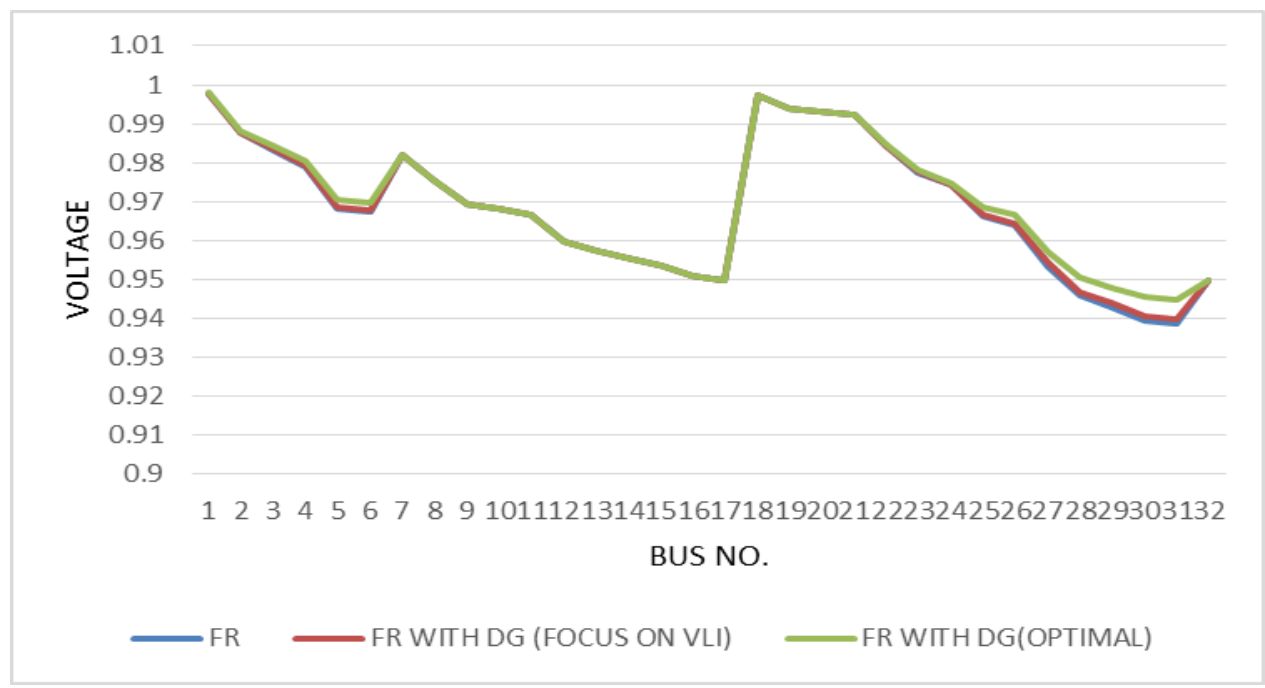

Figure 10. 33 Bus-Voltage Profile V/S Bus Number under Feeder Reconfiguration

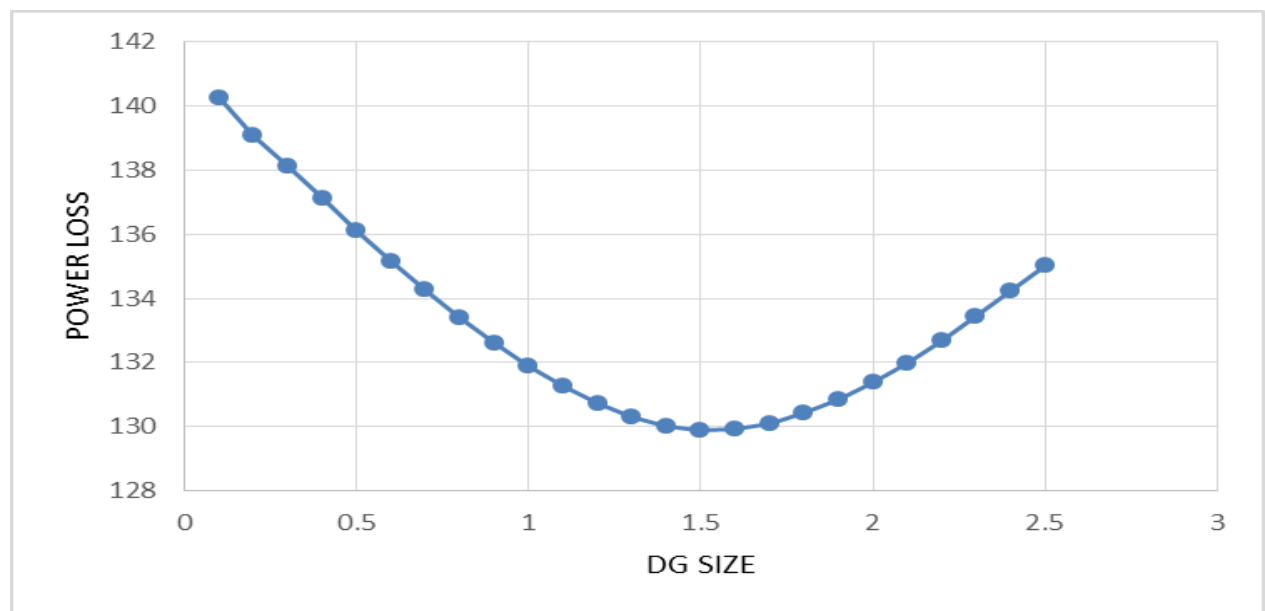

Figure 11. 33 bus-Real Power Loss v/s DG Size under Feeder Reconfiguration 


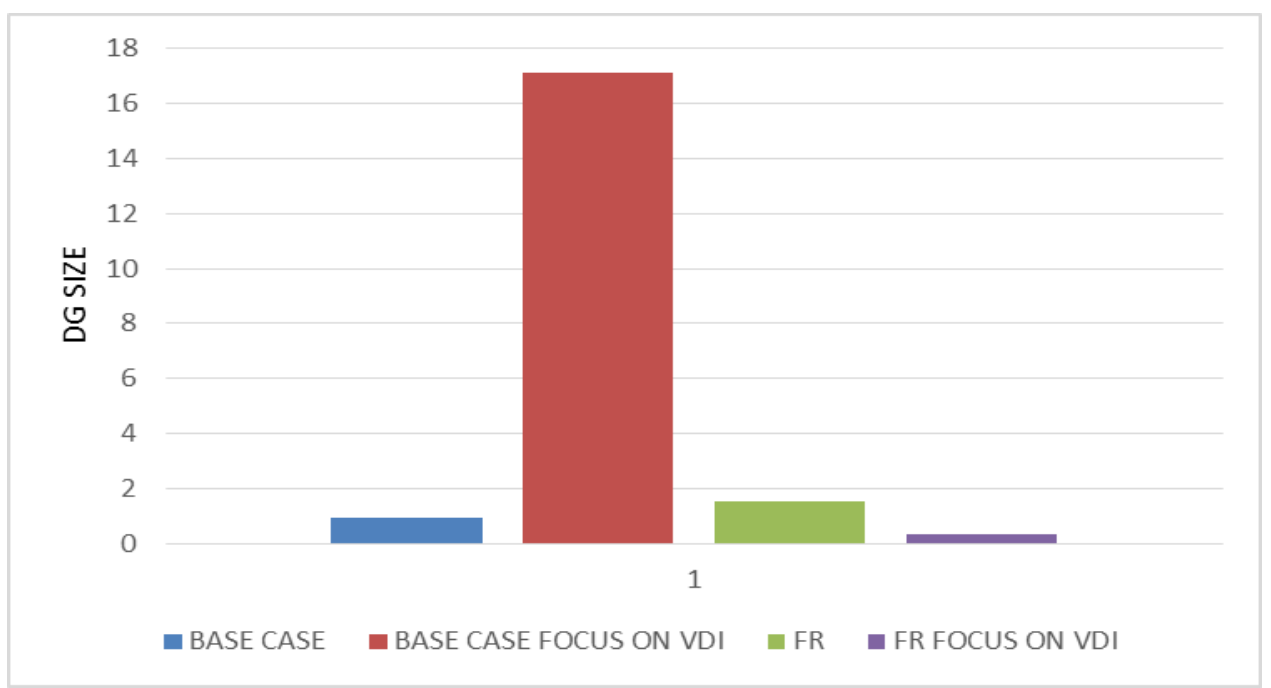

Figure 12. 33 Bus-Size of DG for Base Case and Feeder Reconfiguration

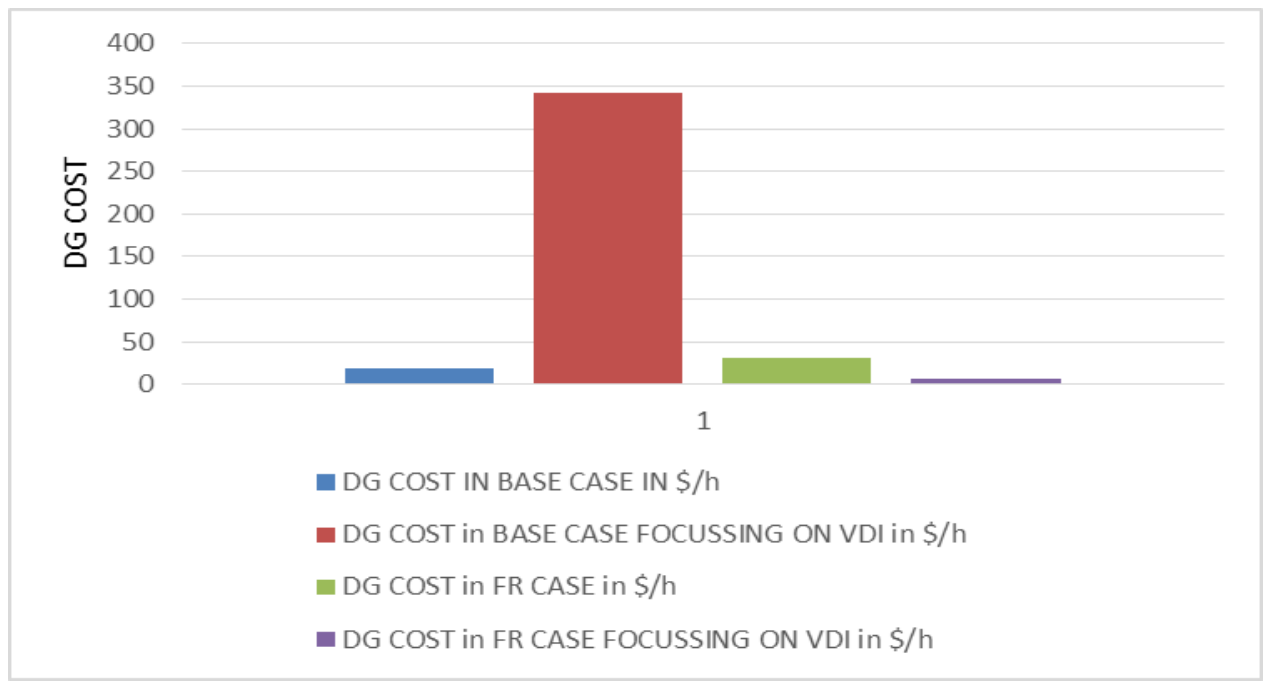

Figure 13. 33 Bus-Cost of DG under Base Case and Feeder Reconfiguration

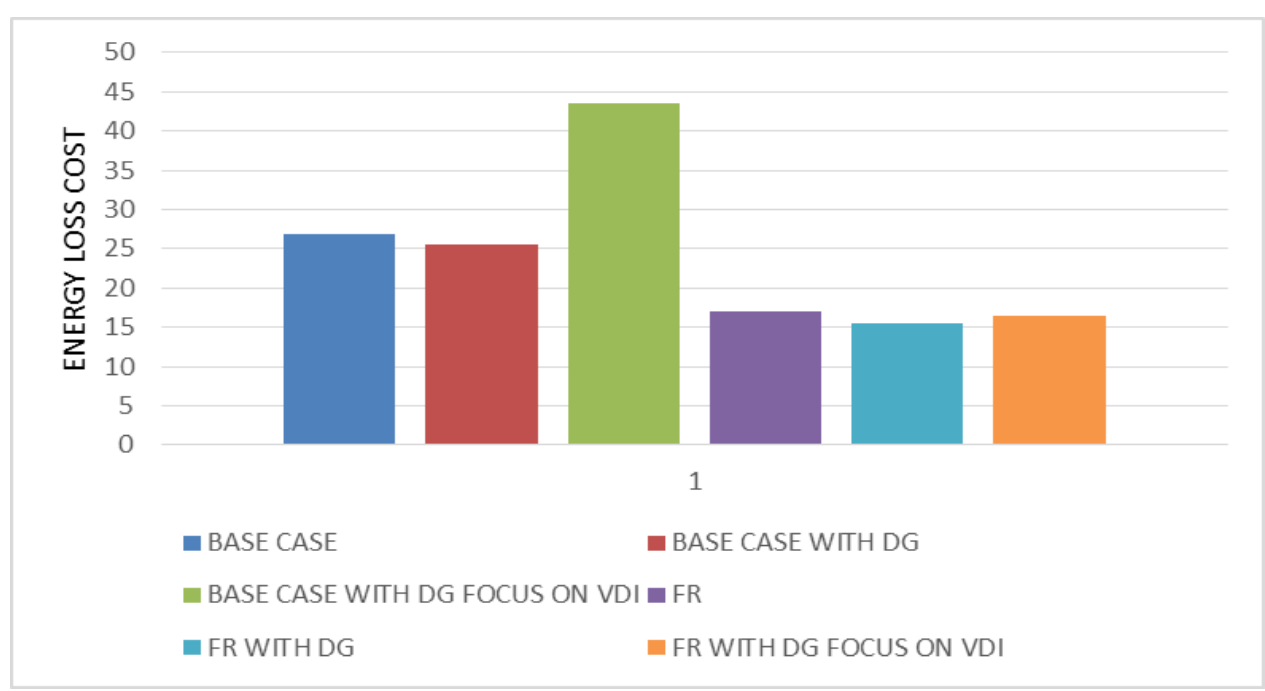

Figure 14. 33 bus-Cost of Energy Losses under base case and Feeder Reconfiguration Cases 


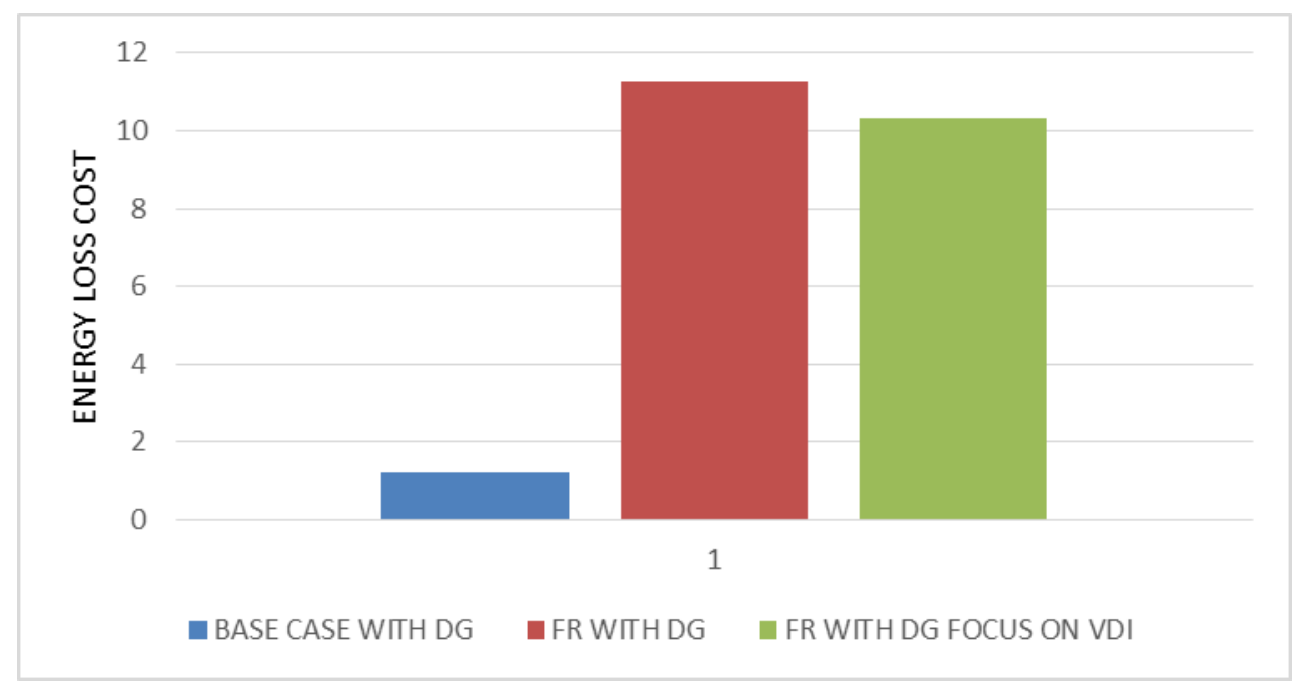

Figure 15. 33 Bus-Savings in Cost of Energy Losses Under Base Case and Feeder Reconfiguration

\subsection{9- Bus Test System:}

For 69 -bus RDS, Substation voltage $=12.66 \mathrm{kV}$, Active power load=3.8014MW, Reactive power load $=2.6936$, and Voltage limit $=1.00 \mathrm{pu}$. As explained for 33-bus test distribution system in the similar way the same procedure is carried out for 69-bus test distribution system shown in Table 2 . As per the below tabulation 2 while performing the load flow, it was observed that real power loss K.W $\left(P_{L}\right)=216.6168$, Reactive power loss $\operatorname{K} \cdot \operatorname{Var}\left(Q_{L}\right)=98.0373$. Base case with and without DG is shown in Figure 17 and 18.Under the initial configuration state with $65^{\text {th }}$ bus as minimum voltage profile location $V_{65}=0.9134$.

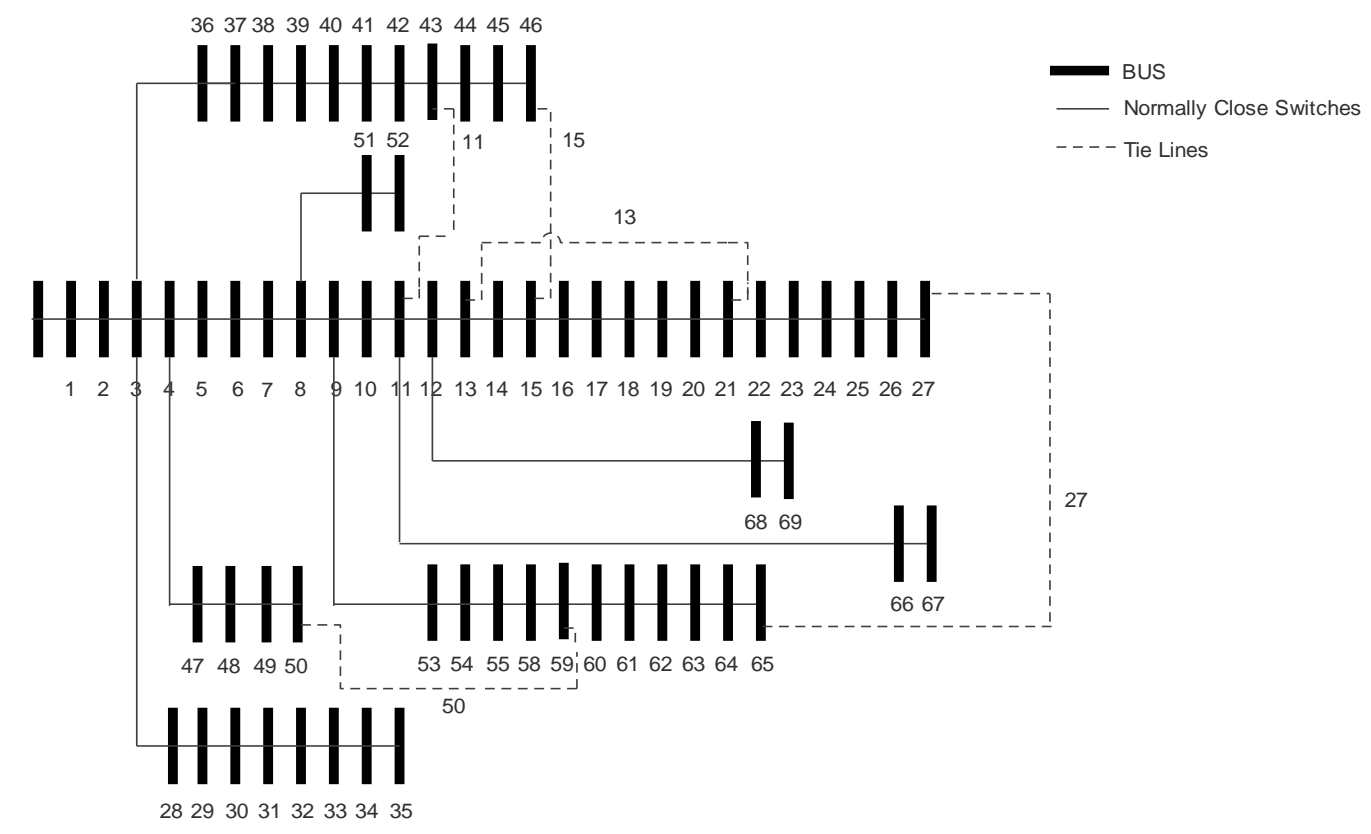

Figure 16. Schematic Diagram of IEEE 69-Bus Test System 
The VLI is obtained as 3.8562 for which the DG was suggested (figure 19). The cost of energy loss is calculated as 25.9940. Real Power Loss versus DG size is shown in figure 20 .

Table 2. Results Obtained For 69-Bus Test System Using VLI

\begin{tabular}{|c|c|c|c|c|c|c|}
\hline Parameters & Base case & $\begin{array}{l}\text { Base case } \\
\text { with DG }\end{array}$ & $\begin{array}{l}\text { Base case } \\
\text { with DG } \\
\text { along VLI }\end{array}$ & FR & $\begin{array}{c}\text { FR with } \\
\text { DG }\end{array}$ & $\begin{array}{c}\text { FR with } \\
\text { DG along } \\
\text { VLI }\end{array}$ \\
\hline $\begin{array}{c}\text { DG } \\
\text { location }\end{array}$ & ----- & 65 & 65 & ---- & 65 & 65 \\
\hline $\begin{array}{c}\text { DG size } \\
(\mathrm{MW})\end{array}$ & ---- & 0.63 & 6.5 & ---- & 0.61 & 0.225 \\
\hline $\begin{array}{l}\text { Total real } \\
(\text { K.W }) P_{L}\end{array}$ & 216.6168 & 210.2905 & 308.9161 & 130.1248 & 126.5560 & 139.5175 \\
\hline $\begin{array}{c}\text { Total } \\
(\text { K.Var }) Q_{L}\end{array}$ & 98.0373 & 95.3577 & 137.3537 & 124.2833 & 121.0370 & 132.6654 \\
\hline $\begin{array}{c}\text { Min. bus } \\
\text { voltage } \\
\text { @ bus }\end{array}$ & $\begin{array}{l}0.9134 \\
@ 65\end{array}$ & $\begin{array}{l}0.9166 \\
@ 65\end{array}$ & $\begin{array}{l}0.9403 \\
@ 61\end{array}$ & $\begin{array}{l}0.9329 \\
@ 65\end{array}$ & & $0.94 @ 64$ \\
\hline VLI & 3.8562 & 3.0197 & 0 & 0.1680 & 0.0798 & 0 \\
\hline $\begin{array}{c}\text { Cost of } \\
P_{D G}(\$ / \mathrm{hr})\end{array}$ & ----- & 12.85 & 130.25 & ---- & 12.45 & 14.7 \\
\hline $\begin{array}{c}\text { Cost of } \\
\text { energy loss } \\
(\$ / \mathrm{hr})\end{array}$ & 25.9940 & 25.2348 & 37.0699 & 15.6149 & 15.1867 & 16.7421 \\
\hline $\begin{array}{l}\text { Savings in } \\
\text { cost of } \\
\text { energy loss }\end{array}$ & ---- & 0.7592 & $\begin{array}{c}\text { Not } \\
\text { applicable }\end{array}$ & ---- & 10.8073 & 9.2519 \\
\hline
\end{tabular}

The Feeder Reconfiguration with and without DG for 69 bys were shown in figure 21 and 22. For the same case as it was identified $65^{\text {th }}$ location with minimum voltage profile as 0.9185 which can be taken as location of allocating DG with size 0.63 we are getting $P_{L}=210.2905, Q_{L}=141.8570 \mathrm{~K}$. Var at $18^{\text {th }}$ bus. The VLI obtained is 3.0197 (figure 23). Real Power Loss versus DG size under Feeder Reconfiguration case is shown in figure 24.But even when losses are reduced the savings obtained from the energy loss cost is only around $0.7592 \$ / \mathrm{hr}$, with cost for the DG as $12.85 \$ / \mathrm{hr}$. When it is observed with DG along with VLI the savings occurred for the initial configuration was very less since the DG size was too high even though VLI has reached zero. So it recommended for doing Feeder Reconfiguration (FR) for the same network it was observed that there is more loss reduction compared to initial configuration $P_{L}=130.1248, Q_{L}=124.2833, V_{\min }=0.9329$, $\mathrm{VLI}=0.1680 \mathrm{where}$ it is $95.64 \%$ compared to the initial configuration and the cost of energy loss is obtained as 15.6149 which is $39.92 \%$ compared to the base case still since voltage have not reached the limitation of 0.94 under FR state. DG were suggested to the network. Voltage Profile versus Bus number for Base Case and Feeder Reconfiguration case is shown in figure 25 and 26 . The location allocated for DG is $30^{\text {th }}$ bus with the DG size of $1.5 \mathrm{MW}$ at cost of $12.45 \$ / \mathrm{hr}$ even though with the minimum voltage is at $32^{\text {nd }}$ bus $P_{L}=126.5560, Q_{L}=121.0370$ and cost of energy is calculated as $15.1867 \$ / \mathrm{hr}$ with the savings of $10.8073 \$ / \mathrm{hr}$. since the work is focussing on significance of VLI to maintain 
$0.94 \mathrm{pu}$ the DG size required is $0.225 \mathrm{MW}$ instead of $0.61 \mathrm{MW}$ as in the earlier case the results obtained $P_{L}=139.5175, Q_{L}=132.6654$ with cost of DG as $14.7 \$ / \mathrm{hr}$ even though the results for savings in FR with DG along VLI is comparatively lesser than FR with DG case but the cost of DG increases profit $62.24 \%$. The size of DG and cost of energy losses are shown in Figure 27 and 28. Figure 29 represents the savings in cost of energy losses.

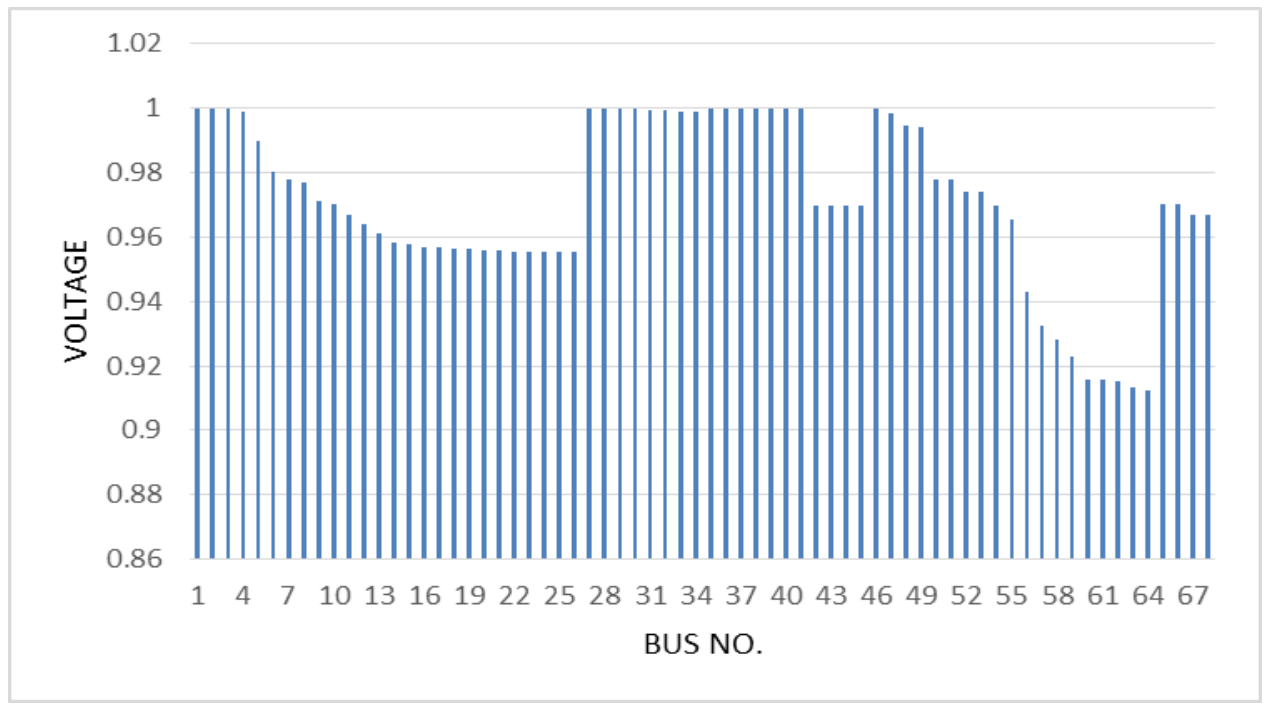

Figure 17. 69 Bus-Base Case Without DG

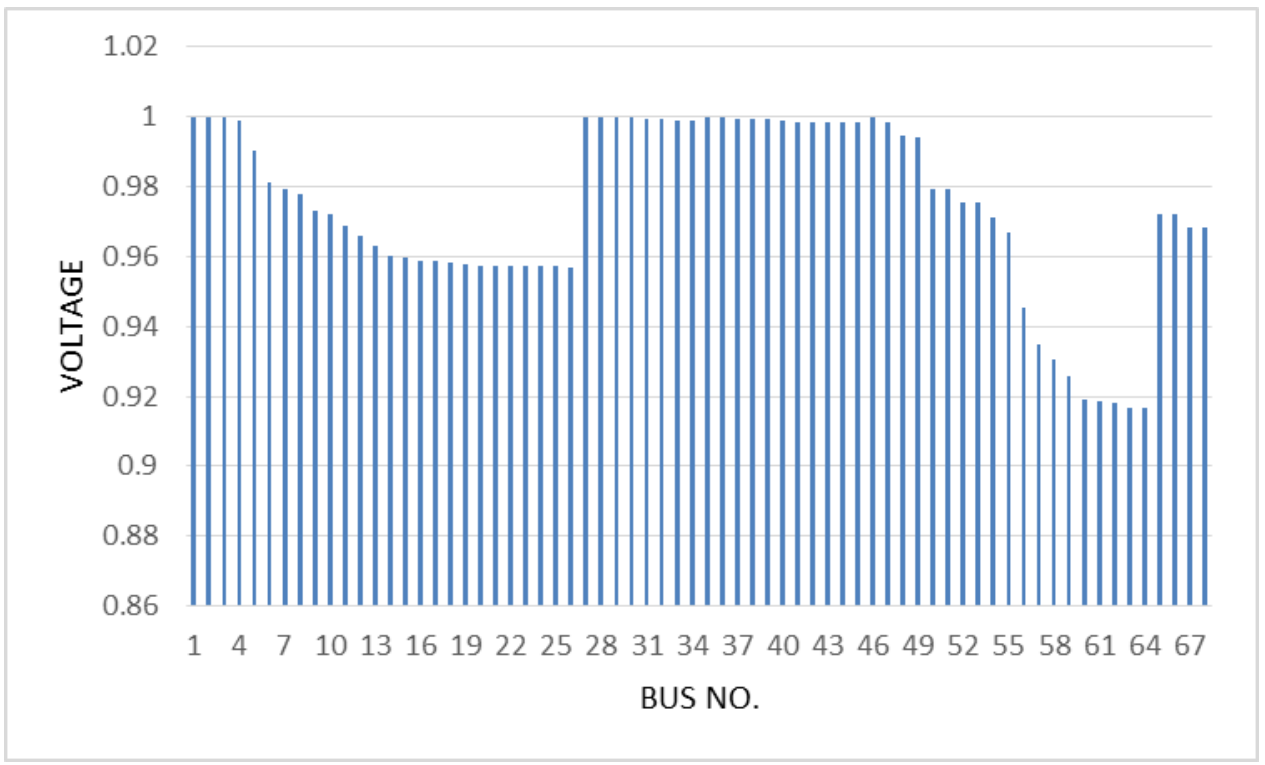

Figure 18. 69 Bus-Base Case with DG (Optimal Size) 


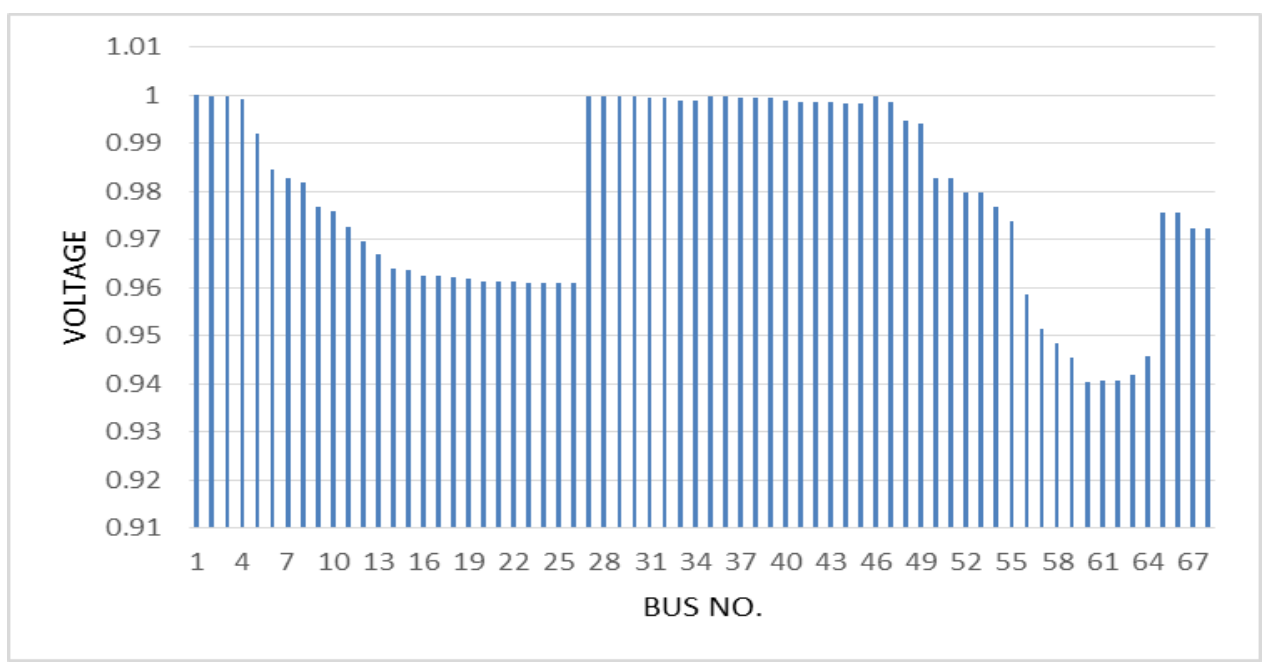

Figure 19. 69 Bus-Base Case with DG Focusing on VLI

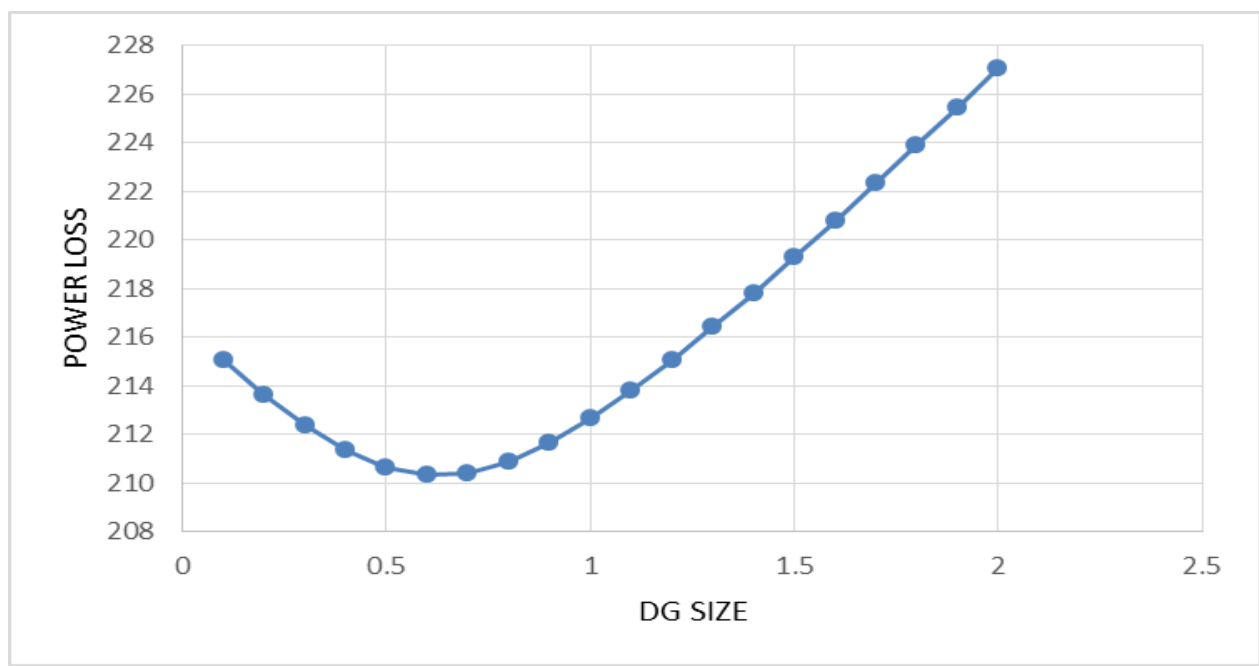

Figure 20. 69 Bus-Real Power Loss V/S DG Size

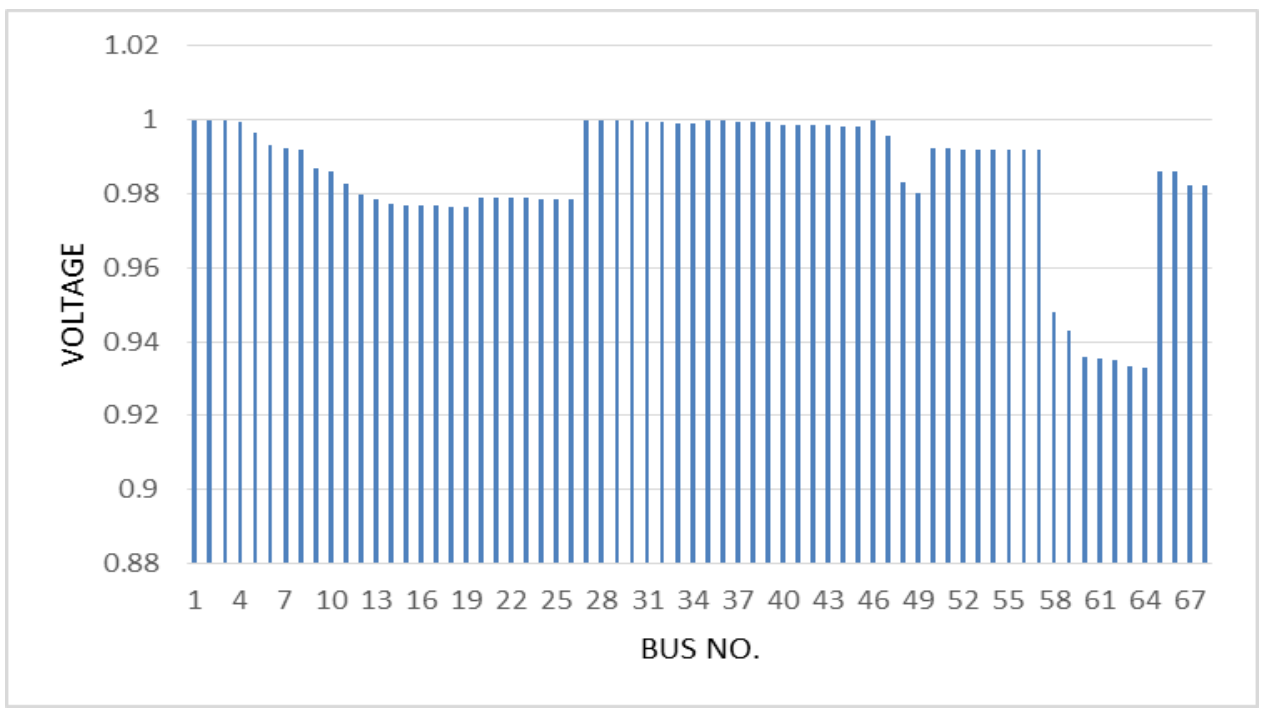

Figure 21. 69 Bus-Feeder Reconfiguration Without DG 


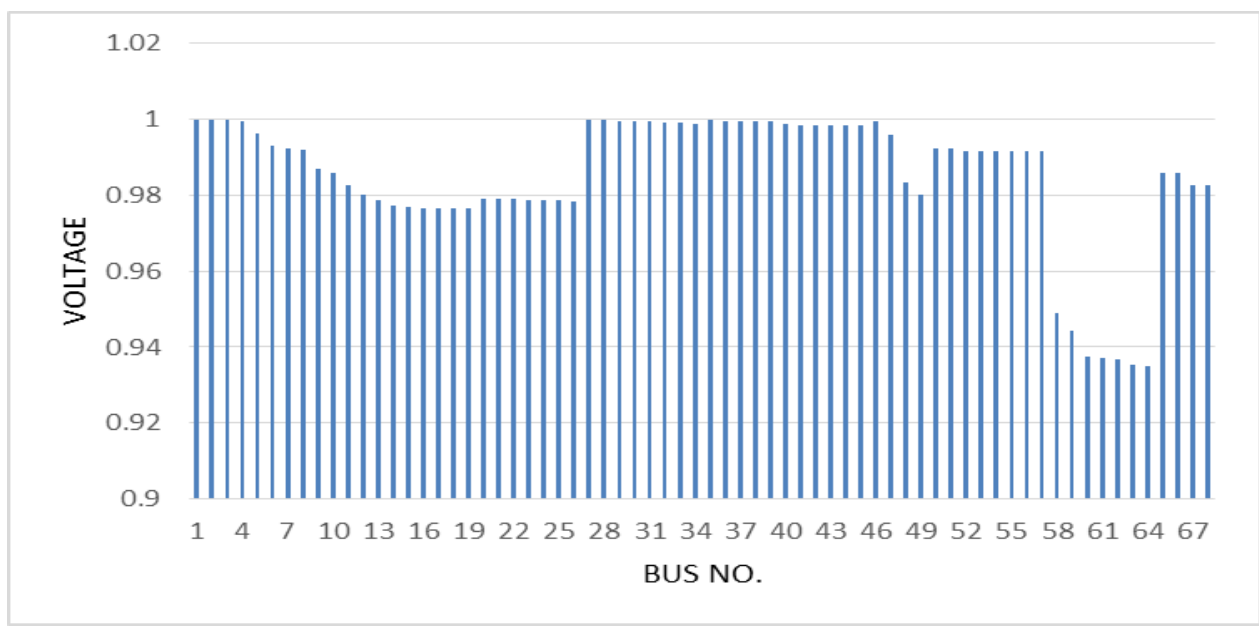

Figure 22. 69 Bus-Fr With Dg (Optimal Size)

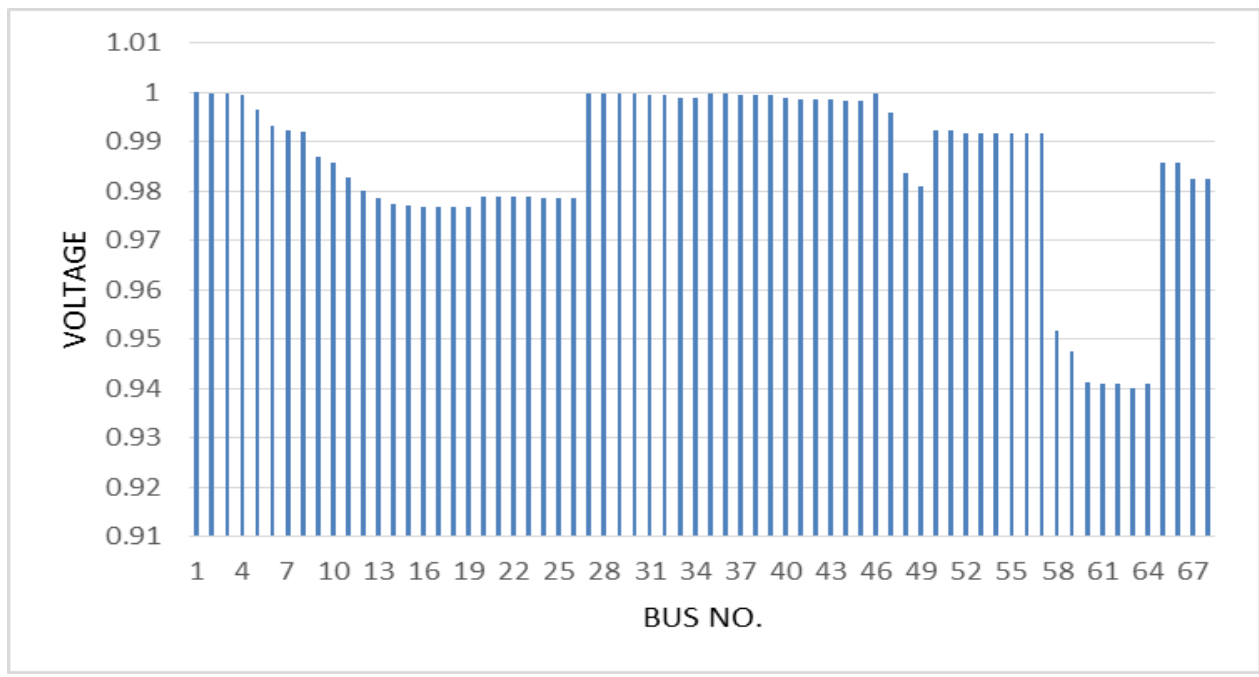

Figure 23. 69 Bus-Feeder Reconfiguration with DG Focusing On VLI

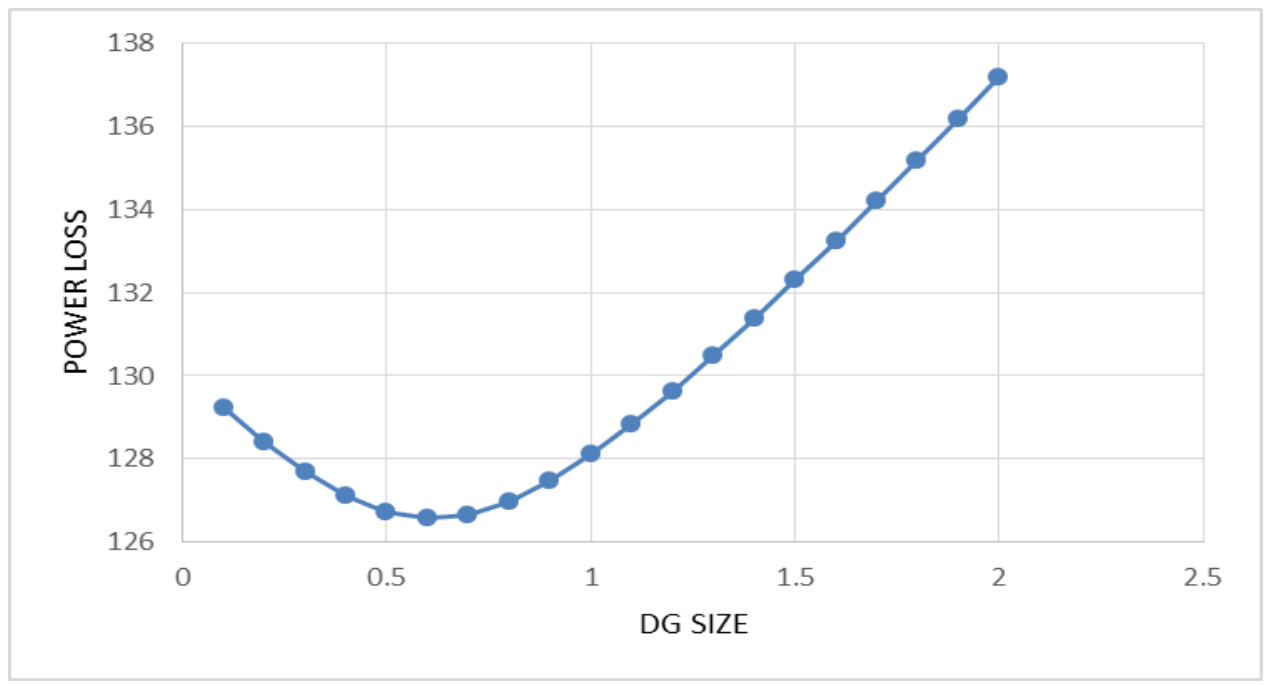

Figure 24. 69 Bus-Real Power Loss V/S DG Size (FR Case) 


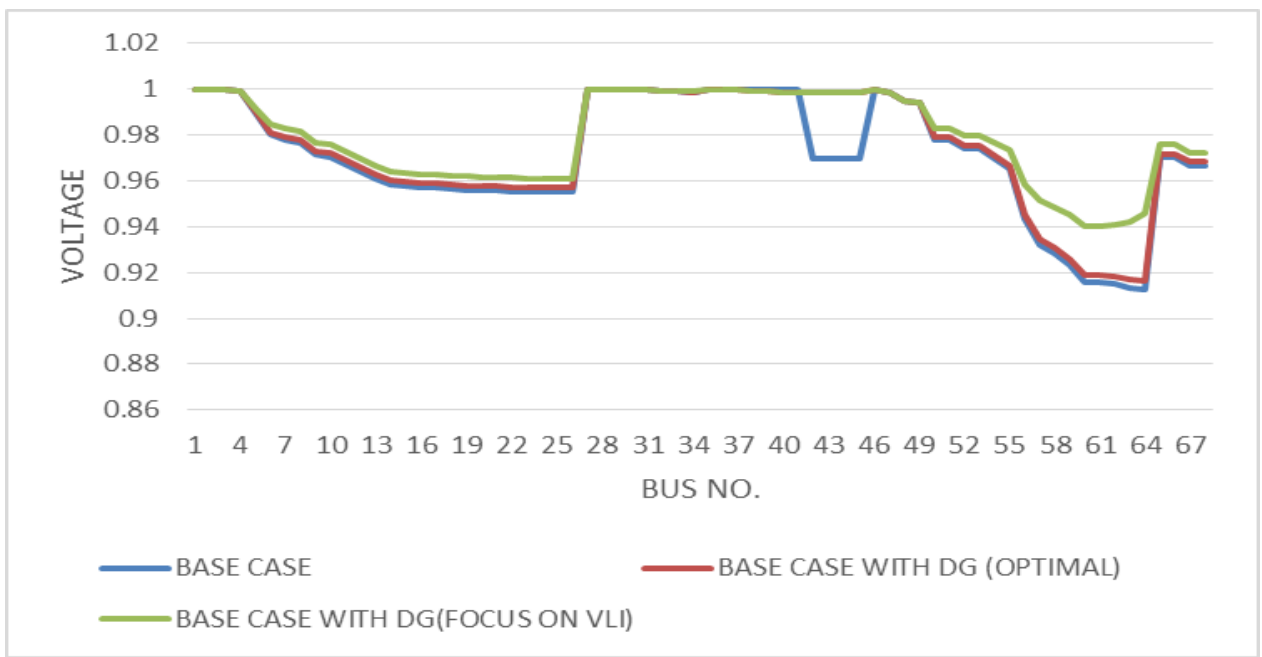

Figure 25. 69 Bus-Voltage Profile V/S Bus Number for Base Case

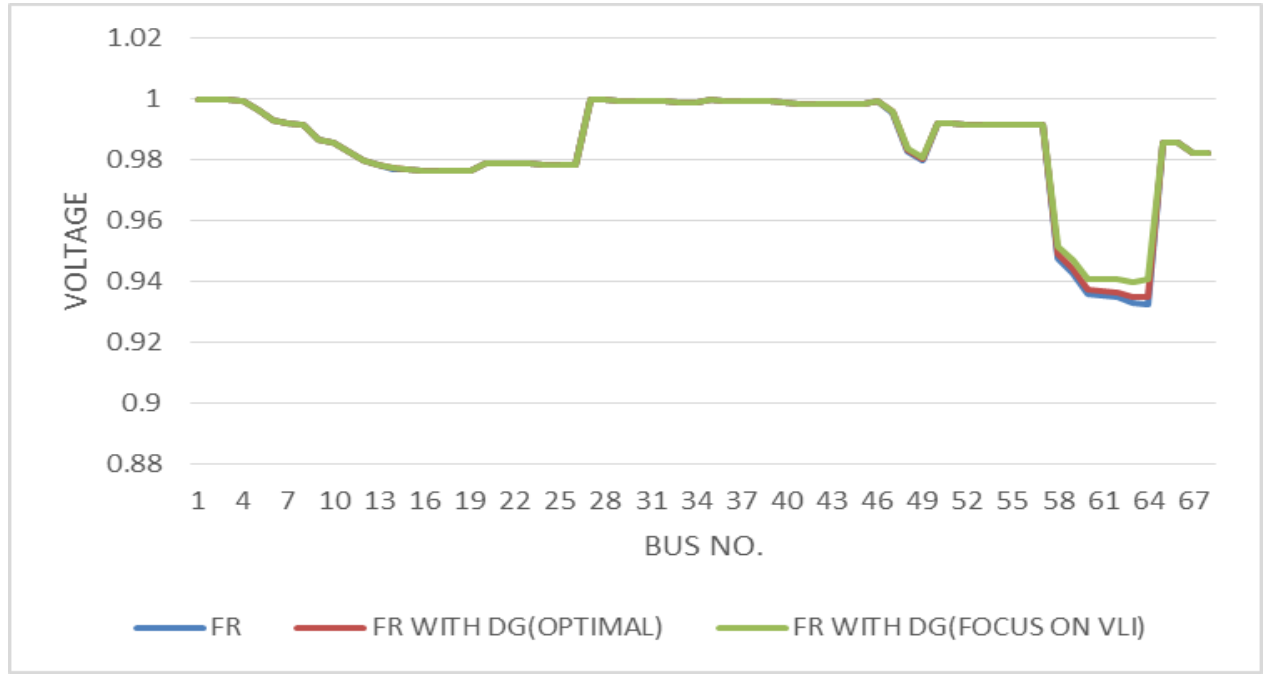

Figure 26. 69 Bus-Voltage Profile V/S Bus Number for Feeder Reconfiguration Case

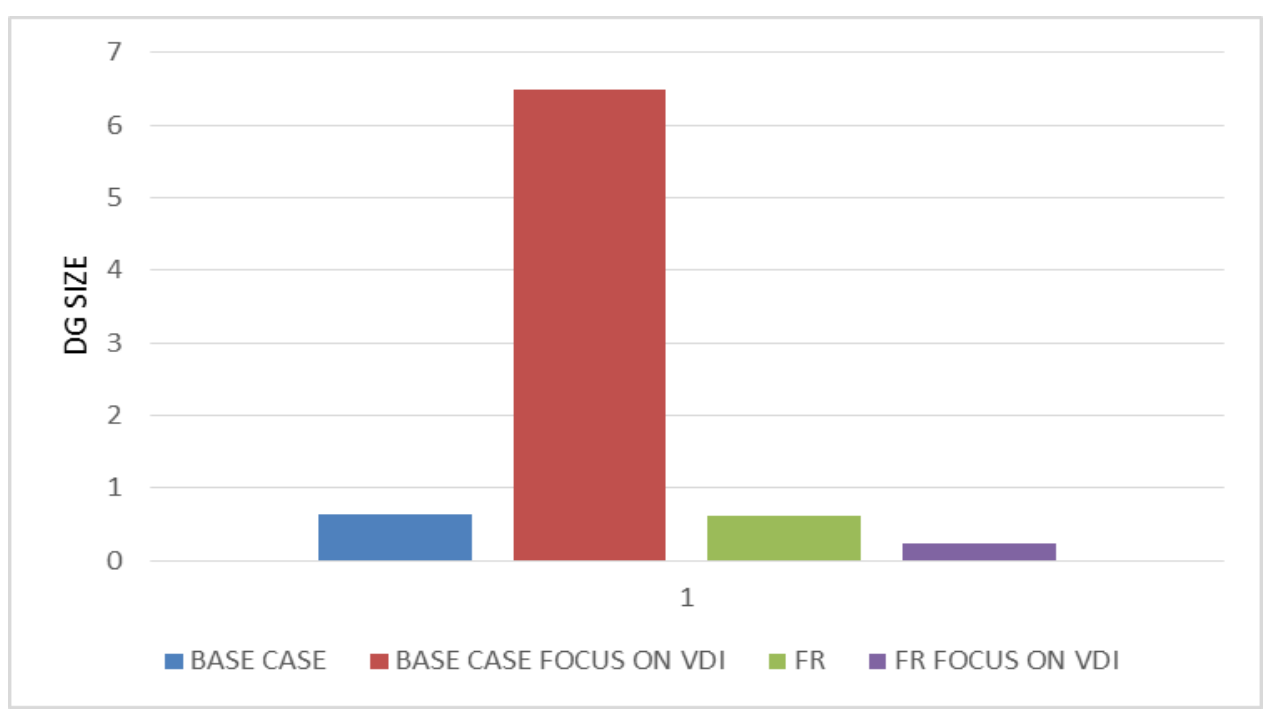

Figure 27. 69 Bus-Size Of DG For Base Case 


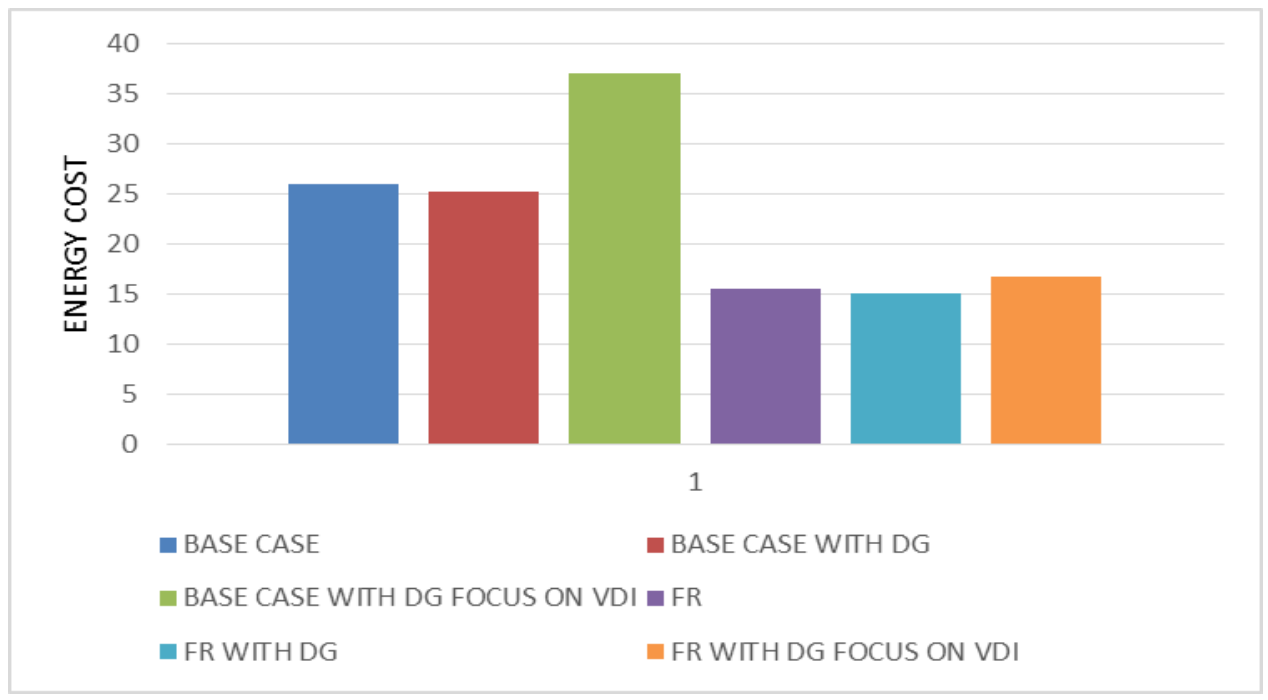

Figure 28. 69 Bus-Cost of Energy Losses

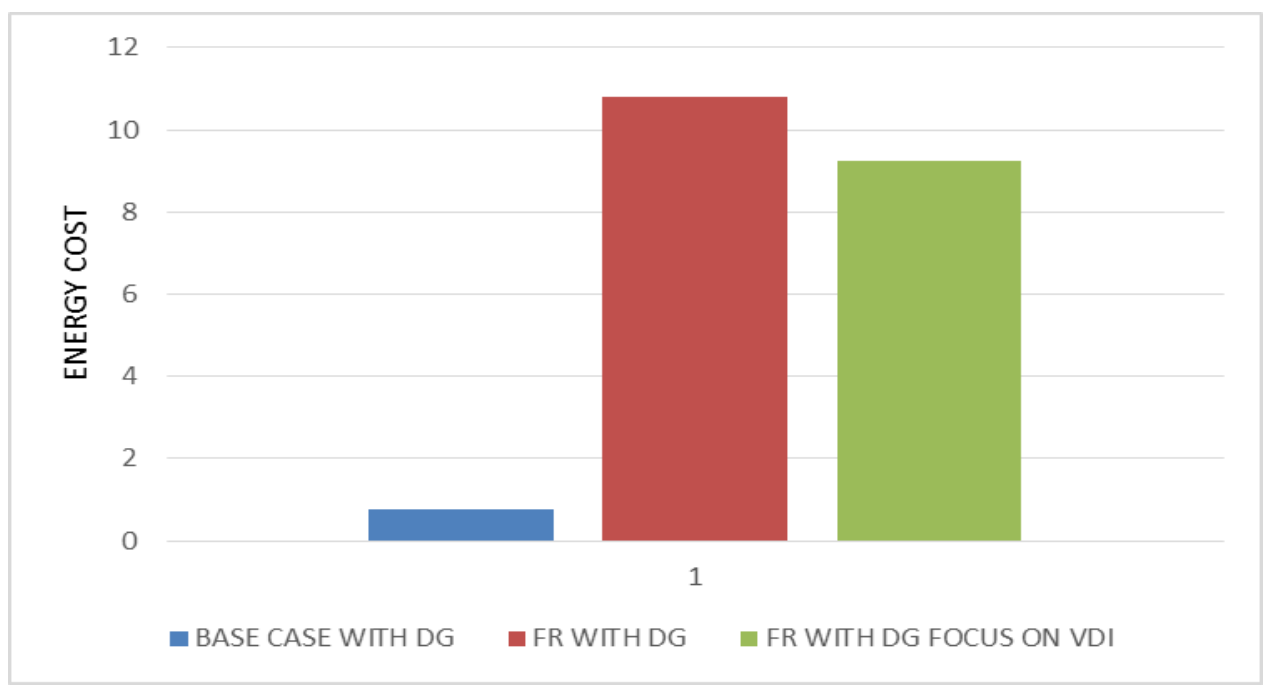

Figure 29. 69 Bus-Savings In Cost Of Energy Losses

\section{Conclusion}

In this paper feeder reconfiguration technique is implemented in distribution system for enhancing the voltage profile. Since voltage profile enhancement is not acquired from base case, base case with DG and FR; from the results obtained it is clear that only under FR with DG case the necessary voltage profile enhancement is achieved. Along with the results it is also noticed that the net profit can be obtained when tested on 33 and 69 bus test distribution system, its states that cost of DG increases with profit of $77.59 \%$ and $62.24 \%$ respectively by considering FR along DG with VLI alone. Since the cost of DG is very less under this case, it is suggested to consider the FR along DG with VLI case to decide the size and location for placing DG appropriately of a given network.

\section{References}

[1] IEEE Standard for,'Interconnecting Distributed Resources with Electric Power Systems", IEEE Std 1547-2003.

[2] Bollen MH, Hassan F.,'Integration of distributed generation in the power system". Piscataway, NJ (USA): IEEE Press; (2011). 
[3] Barker PP, de Mello RW.,"Determining the impact on distributed generation on power systems: Part 1. Radial distribution systems". In: IEEE PES summer meeting, vol. 3; (2000), p. 1645-56.

[4] Tsikalakis AG, Hatziargyriou ND,'Environmental benefits of distributed generation with and without emissions trading"Energy Policy (2007);35:3395-409.

[5] Sayyid Mohssen Sajjadi, Mahmoud-Reza Haghifam, Javad Salehi.,"Simultaneous placement of distributed generation and capacitors in distribution networks considering voltage stability index". Electrical Power and Energy Systems 46 (2013) 366-375.

[6] V.V.S.N. Murthy, Ashwani Kumar."Comparison of optimal DG allocation methods in radial distribution systems based on sensitivity approaches". Electrical Power and Energy Systems 53 (2013) 450-467.

[7] Peyman Karimyan, G.B. Gharehpetian a, M. Abedi , A. Gavili,'Long term scheduling for optimal allocation and sizing of DG unit considering load variations and DG type". Electrical Power and Energy Systems 53 (2013) 450-467.

[8] Ruhaizad Ishak, Azah Mohamed, Ahmed N. Abdalla, Mohd Zamri Che Wanik. "Optimal placement and sizing of distributed generators based on a novel MPSI index". Electrical Power and Energy Systems 60 (2014) 389-398.

[9] M.M. Aman, G.B. Jasmon , A.H.A. Bakar, H. Mokhlis.” A new approach for optimum simultaneous multi-DG distributed generation Units placement and sizing based on maximization of system loadability using HPSO (hybrid particle swarm optimization ) algorithm".Energy 66 (2014) 202-215.

[10] M.M. Aman, G.B. Jasmon, H. Mokhlis, A.H.A. Bakar.” Optimal placement and sizing of a DG based on a new power stability index and line losses". Electrical Power and Energy Systems 43 (2012) 12961304.

[11] M.H. Moradi , M. Abedini."A combination of genetic algorithm and particle swarm optimization for optimal DG location and sizing in distribution systems". Electrical Power and Energy Systems 34 (2012) 66-74.

[12] N. Mohandas, R. Balamurugan, L. Lakshminarasimman."Optimal location and sizing of real power DG units to improve the voltage stability in the distribution system using ABC algorithm united with chaos". Electrical Power and Energy Systems 66 (2015) 41-52.

[13] B. Bakhshideh Zad, H. Hasanvand, J. Lobry, F. Vallée.” Optimal reactive power control of DGs for voltage regulation of MV distribution systems using sensitivity analysis method and PSO algorithm". Electrical Power and Energy Systems 68 (2015) 52-60.

[14] Satish Kansal, Vishal Kumar, Barjeev Tyagi. "Optimal placement of different type of DG sources in distribution networks". Electrical Power and Energy Systems 53 (2013) 752-760

[15] Wanlin Guan, Yanghong Tan, Haixia Zhang, Jianli Song."Distribution system feeder reconfiguration considering different model of DG sources". Electrical Power and Energy Systems 68 (2015) 210-221.

[16] Srinivasa Rao Gampa, D. Das. "Optimum placement and sizing of DGs considering average hourly variations of load". Electrical Power and Energy Systems 66 (2015) 25-40.

[17] Rajkumar Viral, D.K. Khatod. "Optimal planning of distribute d generation systems in distribution system :A review". Renewable and Sustainable Energy Reviews 16 (2012) 5146-5165.

[18] Seyed Abbas Taher, Mohammad Hossein Karimi. "Optimal reconfiguration and DG allocation in balanced and unbalanced distribution system."Ain Shams Engineering Journal (2014) 5, 735-749.

[19] An D.T Le, M. A. Kashem, M. Negnevitsky, G. Ledwich,Maximising "Voltage Support in Distribution Systems by Distributed Generation".

[20] Kazem Haghdar, Heidar Ali Shayanfar. "Optimal Placement and Sizing of DG and Capacitor for the Loss Reduction via Methods of Generalized Pattern Search and Genetic Algorithm”.

[21] Chandrasekhar Yammani, Sydulu Maheswarapu, Sailajakumari Matam. Multiobjective Optimization for Optimal Placement and Size of DG using Shuffled Frog Leaping Algorithm. Energy Procedia 14 (2012) $990-995$.

[22] M.M. Aman, G.B. Jasmon, A.H.A. Bakar, H. Mokhlis.”A new approach for optimum DG placement and sizing based on voltage stability maximization and minimization of power losses". Energy Conversion and Management 70 (2013) 202-210.

[23] M. Kefayat, A. Lashkar Ara, S.A. Nabavi Niaki. "A hybrid of ant colony optimization and artificial bee colony algorithm for probabilistic optimal placement and sizing of distributed energy resources". Energy Conversion and Management 92 (2015) 149-161.

[24] Duong Quoc Hung, N. Mithulananthan.” Loss reduction and loadability enhancement with DG: A dualindex analytical approach". Applied Energy 115 (2014) 233-241.

[25] Hasan Doagou-Mojarrad, G.B. Gharehpetian, H. Rastegar, Javad Olamae. "Optimal placement and sizing of DG (distributed generation) units in distribution networks by novel hybrid evolutionary algorithm". Energy 54 (2013) 129e138.

[26] Augusto C. Rueda-Medina, John F. Franco, Marcos J. Rider, Antonio Padilha-Feltrin, Rubén Romero."A mixed-integer linear programming approach for optimal type, size and allocation of distributed generation in radial distribution systems". Electric Power Systems Research 97 (2013) 133143.

[27] Sayyad Nojavan, Mehdi Jalali, Kazem Zare.”Optimal allocation of capacitors in radial/mesh distribution systems using mixed integer nonlinear programming approach”. Electric Power Systems Research 107 (2014) 119-124. 
[28] Shan Cheng, Min-You Chen, Peter J. Fleming.’'Improved multi-objective particle swarm optimization with preference strategy for optimal DG integration into the distribution system". Neurocomputing 148 (2015) 23-29.

[29] S. Devi, M. Geethanjali. "Application of Modified Bacterial Foraging Optimization algorithm for optimal placement and sizing of Distributed Generation”. Expert Systems with Applications 41 (2014) $2772-2781$.

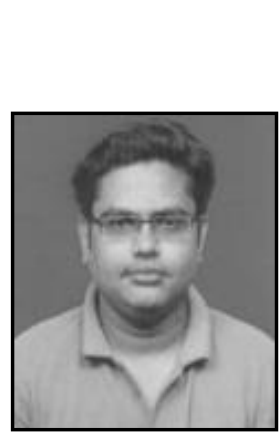

\begin{abstract}
Authors
S Vidyasagar currently working as Assistant Professor in the EEE Department at SRM University, Chennai, India. He received M.E in Power systems from Anna University in the year 2005. He is currently pursuing his $\mathrm{PhD}$ degree at SRM University in the area of Feeder Reconfiguration with DG placement in Distributed Systems. His area of interest includes Power System Operation and Control, FACTS and Power System Protection.
\end{abstract}

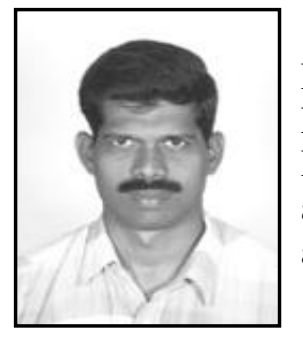

K Vijayakumar currently working as Professor and Head in EEE Department at SRM University, Chennai, India. He has received his $\mathrm{Ph} . \mathrm{D}$ degree in SRM University in the area of Deregulation systems. His area of research interests includes Computational Intelligence applications in Power Systems, FACTS and Power System Operation and Control.

R Ramanujam is currently working as professor in EEE department at SRM University, Chennai, India. He received Ph.D from IISC Bangalore. His area of interest includes Modeling of Power System components, Power System Stability and Transients.

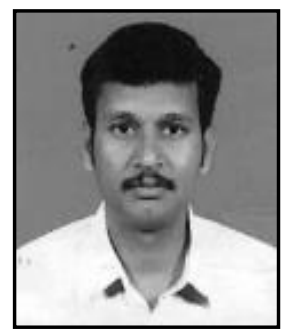

D. Sattianadan currently working as Assistant Professor in the EEE Department at SRM University, Chennai, India. He received his $\mathrm{Ph} . \mathrm{D}$ in area of Power systems from SRM University in the year 2015. His area of interest includes Distributed Generations, Power System Operation and Control, FACTS and Power System Protection.

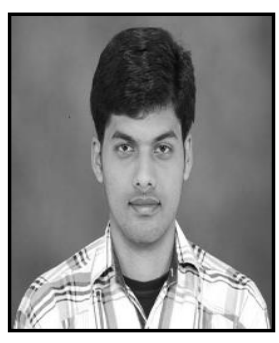

S Noraj Kumar is pursuing his M.Tech in Electrical Engineering at SRM university, Chennai, India. He completed his B.Tech from JNTUA in the year 2013.His area of interest includes Distributed Generation. 
International Journal of Control and Automation Vol. 8, No. 6 (2015) 